\title{
LA CONCEPCIÓN DEL ESCLAVO EN EL MUNDO CLÁSICO GRIEGO: FORMAS HETEROGÉNEAS DE SUJECIÓN EN LA PRÁCTICA HELÉNICA DE LA ESCLAVITUD
}

\author{
Daniel Santibáñez - Guerrero \\ Universidad Miguel de Cervantes. Chile
}

Resumen: A partir de la amplia gama de términos utilizados por los antiguos griegos para aludir al esclavo, durante décadas los helenistas interpretarán esa falta de precisión como un rasgo propio de la desprolija concepción griega sobre la esclavitud, dificultando directamente su examen por parte de los mismos estudiosos modernos. Con el trabajo de Detlef Lotze (1930-2018) a mediados del siglo pasado, sin embargo, esta pluralidad de conceptos en torno al esclavo empieza a interpretarse como un indicio de la complejidad con la que la esclavitud se concibe y aplica en el mundo griego, la cual, finalmente consistiría en formas heterogéneas de sujeción y no a una institución universalmente delimitada y ejercida. Los conceptos "esclavitud-dependencia" y "esclavitud-mercancía", de este modo, adquieren relevancia para identificar la necesaria diferencia entre una forma de esclavitud donde el esclavo administra el proceso productivo, y otra donde participa únicamente como elemento material del mismo.

Palabras clave: esclavitud - Grecia - conceptos - dependencia - mercancía.

\section{THE CONCEPTION OF THE SLAVE IN THE CLASSICAL GREEK WORLD: HETEROGENEOUS FORMS OF SUBJECTION IN THE HELLENIC PRACTICE OF SLAVERY}

Abstract: Based on the wide range of terms used by the ancient Greeks to refer to the slave, for decades the Hellenists will interpret this lack of precision as a characteristic of the untidy Greek conception of slavery, making it directly difficult for the same scholars to examine. modern. With the work of Detlef Lotze (1930-2018) in the middle of the last century, however, this plurality of concepts around the slave begins to be interpreted as an indication of the complexity with which slavery is conceived and applied in the Greek world, the which, finally, would consist of heterogeneous forms of subjection and not a universally defined and exercised institution. The concepts «slavery-dependence» and "slaverymerchandise», thus, acquire relevance to identify the necessary difference between 
a form of slavery where the slave manages the production process, and another where he participates only as a material element of it.

Keywords: slavery - Greece - concepts - dependency - merchandise.

Recibido: 31.12.2020 - Aceptado: 05.05.2021

Correspondencia: Daniel Santibáñez Guerrero.

Email: dsantibanezguerrero@gmail.com

Doctor en Filosofía, Universidad de Chile.

Docente en Universidad Miguel de Cervantes, Chile.

\section{Introducción:}

n hecho ampliamente comentado y compartido entre los
estudiosos del mundo antiguo es la condición de institución
política y social que la esclavitud ostentó en Grecia, interpretándose como una práctica legítima por parte de los propios griegos y ejerciendo, a partir de su aceptación mayoritaria, un rol fundamental en el desarrollo económico, político y cultural que las polis alcanzan en el siglo $\mathrm{V}$ a. C. La evidencia principal de este beneplácito helénico generalizado hacía la aplicación de la esclavitud se encontrará en un importante número de testimonios sobre los pormenores de la vida, el trabajo y las actividades diarias de los esclavos, interactuando con los ciudadanos, hombres libres y extranjeros de la ciudad, como con sus propios pares en el desempeño de las diversas labores a ellos asignadas. Su amplia presencia en la cotidianidad de la vida doméstica, social y política griega, así, lo ratifica como un personaje característico de la vida pública y privada en las polis de la época.

A pesar de la existencia de este nutrido conjunto de testimonios presentes por ejemplo en pasajes de obras épicas, liricas, trágicas, cómicas, históricas, científicas y filosóficas -, resulta altamente llamativo la ausencia casi total de tratados sistemáticos donde la esclavitud se estudie de manera formal, siendo prácticamente la única excepción de esta tendencia el libro I de la Política de Aristóteles. Este hecho, evidentemente, constituye un obstáculo importante para el esclarecimiento de algunos puntos complejos en la investigación moderna sobre la esclavitud, puntos que, en términos generales, involucran la determinación del origen histórico preciso de esta práctica (posiblemente relacionada con la costumbre arcaica de robar las mujeres de 
los pueblos derrotados en los conflictos bélicos ${ }^{1}$ ), la fijación de la cantidad exacta de esclavos dentro de las polis (problema en torno al cual se suscitarán posiciones encontradas entre varios de los principales investigadores), y la delimitación clara del tipo de trabajo desarrollado por éstos (los cuales, de acuerdo a las descripciones ofrecidas por algunas fuentes antiguas, en muchos casos desempeñan funciones similares a las realizadas por sus amos o los demás hombres libres de la ciudad).

Dentro de estas dificultades, la arista vinculada con la semántica emerge como un foco de investigación fundamental a mediados del siglo XX. Tal arista, en gran medida, se concentrará en la aparente impresión terminológica que los griegos de aquel periodo evidenciarían al momento de referirse a los esclavos, los cuales son aludidos mediante un conjunto variado de términos que, en su mayoría, no presentan significados equivalentes. Con ello, tanto la noción como la labor y el recurso de legitimidad de la sujeción de los esclavos presentaría un carácter ambiguo, el cual, de forma paralela, dificulta el estudio de esta importante institución griega por parte de los estudiosos modernos que, en su mayoría, terminan por asumir esta ambigüedad como un rasgo deficitario propio de la visión helénica de la esclavitud.

El contrapunto formal de esta última interpretación se encuentra en el trabajo del historiador y filólogo clásico alemán Detlef Lotze (1930-2018), autor de Metaxý Eleutherôn kai Doulôn (1959). En contraste con la tesis que atribuye una falta de claridad a la noción helénica de la esclavitud, Lotze sugiere que la amplia variedad de términos empleados por los griegos para referirse a los esclavos daría cuenta de la existencia de "formas de sujeción heterogenias" en la práctica histórica de la esclavitud, las cuales se habrían desarrollado bajo diversas modalidades al interior de cada polis en razón de su sabida autonomía política, económica y jurídica. De ser así, la esclavitud no habría correspondido a una institución delimitada con formas claras y generales y, por ello, no se habría aplicado del mismo modo en todo el terreno griego.

De este modo, el presente trabajo tiene por objetivo indagar de forma general en las posibilidades que la propuesta de Lotze entregan a la investigación

1 Patterson (1993: 90-94) Ya en la sociedad homérica la esclavización de las mujeres de los enemigos derrotados en la guerra se asume, entre los griegos, como un símbolo de superioridad y representación del triunfo. Y es que, a diferencia del hombre que después de ser apresado, comúnmente era torturado y ejecutado, la mujer constituye un preciado botín de guerra, cuyo destino mayoritariamente era el desarrollo de labores domésticas o actividades de concubinato al servicio de su nuevo amo, motivo por el cual tanto la mujer apresada como su polis de origen lamentan el sometimiento forzado del cual son víctimas. 
sobre la esclavitud en la Grecia clásica, examinando las fortalezas de esta lectura frente a las dificultades que tradicionalmente se han identificado en la aproximación de los estudiosos a la esclavitud antigua y, particularmente, reflexionando en torno a los fundamentos epistemológicos que sostienen el tipo de investigación filológica que se desarrolla con posterioridad al trabajo lotziano.

\section{Los términos utilizados por los griegos para referirse a los esclavos}

No existe en un único término en el griego antiguo para hacer referencia al "esclavo", esto, a pesar que los distintos conceptos empleados por los helenos en diferentes épocas coinciden en resaltar el contraste entre este esclavo y el

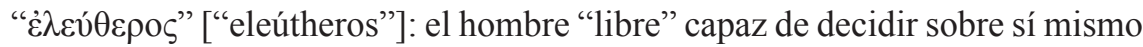
y autogobernarse ${ }^{2}$.

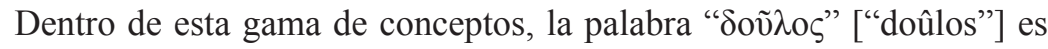
la más recurrente en la denominación del "esclavo": aquel sujeto sometido al mando de otro y, por ende, privado de su libertad. El término " $\delta$ ov $\lambda \varepsilon i ́ a "$ ["douleía"], por su parte, será mayoritariamente traducido por "esclavitud", presentando la misma raíz etimológica que doûlos: los términos micénicos "doero" y "doera". Como explica Pierre Vidal-Naquet (1930-2006), este origen etimológico se ha establecido gracias al desciframiento de tablillas micénicas durante la década de los cincuenta, las cuales confirmarían que el empleo del término "esclavo" para la designación de una suerte de "condición" o "categoría" social, ya se habría utilizado desde el 1550 al 1110 a. C. ${ }^{3}$

Determinar con precisión el origen histórico de esta raíz etimológica resulta complejo, y las teorías desarrolladas son algo discordantes en este punto. Un panorama general de la cuestión es ofrecido por el filólogo clásico español José Miguel Jiménez en el artículo A propósito de la etimología de doûlos (2009):

a) Préstamo de la lengua minorasiática: tesis defendida por Maximilian Lambertz (1882-1963) en el artículo Zur etymologie

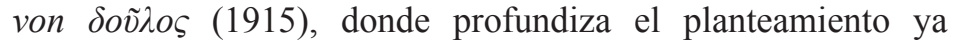
bosquejado en su disertación doctoral en 1907. Lambertz, como explica Jiménez, examina los testimonios del poeta efesio Hiponacte (s. VI a. C.), quien solía incorporar en su prosa numerosos términos de procedencia no griega. Este hecho, junto con la tendencia antigua de emplear etnónimos para referirse

2 Chantraine (1968: 294).

3 Vidal-Naquet (1992: 48-49). 
al esclavo (también presente en los romanos y bizantinos), y la procedencia mayoritaria de éstos de regiones como Tracia, Frigia y Caria, constituirían las principales evidencias de esta hipótesis.

b) Origen en la lengua sánscrita: teoría originalmente bosquejada por Heinrich Düntzer (1813-1901) en Homerische Etymologien, KZ, 16 (1867). Düntzer sugerirá un nexo entre el griego doûlos con el término "dāsá-", empleado en sánscrito para designar al esclavo. En védico "dāsá-" significa "enemigo", "demonio" o "extranjero", vinculándose con "dásyu-" que denomina a los pueblos pre-arios de la India. No obstante, la ausencia de paralelos de "dāsá-" más allá del indoiranio, ha llevado a que estudiosos como Manfred Mayrhofer (1926-2011) en el volumen 2 de Kurzgefasstes etymologisches Wörterbuch des Altindischen (1963), a proponer que "dāsá-" correspondería a una evolución semántica secundaria de "extranjero", que dentro del indo-iranio podría estar relacionada con la raíz de "dấmyati": "domar", "dominar" y "remontar".

c) Origen de raíz indoeuropea: hipótesis desarrollada - entre otros - por Antonio Tovar (1911-1985) en el artículo Indo-European etymology of do-e-ro (1972). Esta teoría relaciona doûlos con la raíz "dem-" (que significa "casa", "familia"), la cual da origen tanto a los términos "domar", "dominar", como "construir". La falta de claridad respecto de la relación de "dem-" con el primer significado, sin embargo, plantea dificultades que Tovar intenta subsanar proponiendo que una evolución a partir de la raíz "dem". Siguiendo esta línea, Günter Neumann (1920-2005) sugiere la unión entre las raíces "dem-" (en el sentido específico de "casa", "familia") y "sel-" ("coger", "capturar"), imprimiendo a doûlos un significado cercano a "prisionero de la casa o familia".

d) "Calco" de origen babilónico: propuesta planteada por Leonard Robert Palmer (1906-1984) en The interpretation of Mycenaean Greek Texts (1963). Palmer emparenta la palabra doûlos con la raíz "do-" (traducida como "dar"), los cuales cual replicaría ("calcaría") la relación entre el termino babilonio shirku ("oblato"), y el verbo sharâku ("dar, donar") del cual surgiría su origen. Este "calco" se introduciría en el micénico donde se 


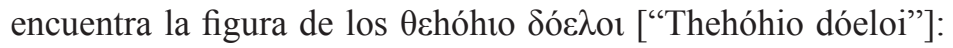
"esclavos de la divinidad" que, al igual que los shirku, son ofrecidos a los dioses por parte de sus dueños o sus padres.

Al margen del debate sobre el origen exacto de la etimología, Pierre Chantraine (1899-1974) sostendrá en el conocido Dictionnaire étymologique de la langue grecque (1968) que el uso de "doûlos" es generalizado en la primera literatura griega: sólo Homero recurrirá a la expresión " $\delta$ où $\lambda$ iov $\tilde{\eta} \mu \alpha \rho$ " [“doùlion emar"], para referirse a la esclavitud, mientras que, para la gran mayoría de los primeros poetas trágicos, el término alude a la persona sometida a un déspota o un tirano. Este hecho, sin embargo, ratificaría a juicio de algunos autores el carácter ambiguo que la designación de los esclavos presenta en esta época (siglo VIII a. C.), señalando que por lo menos en el periodo micénico, la diferenciación entre esclavos y los hombres libres no se habría expresado con total claridad.

Junto con doûlos, otros términos empleados para referirse al eslavo

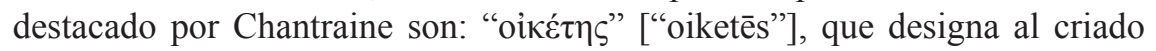
("aquel que vive en la casa"); “ $\sigma \tilde{\omega} \mu \alpha$ "["sôma”], “cuerpo", utilizado normalmente

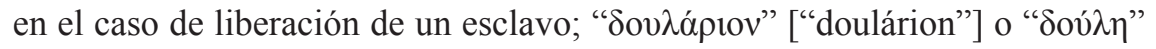

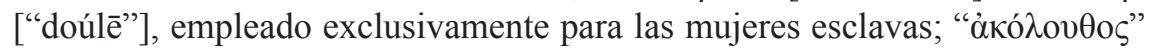
["ákólouthos"], "el que acompaña", que inicialmente alude al sirviente que ayuda al hoplita con su armamento, empleándose con posterioridad al criado

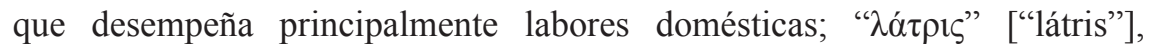
"siervo", "servidor" o "criado", que dentro del contexto griego también serán considerados como esclavos destinados también a las actividades de la casa o

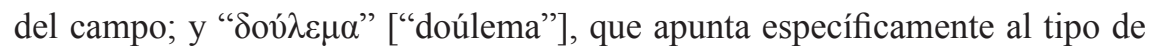
trabajo de exigencia física desarrollado por los esclavos ${ }^{4}$.

El trasfondo común de todos estos conceptos se vincula con la obediencia forzada que ciertos hombres experimentan, encontrándose así a merced de la voluntad y la disposición de otros. Proyectada en la dimensión política y social que adquiere en los siglos V y IV al C., la esclavitud presenta entonces dos rasgos distintivos bien marcados:

Primero, involucra una relación de mando y subordinación que, presente fundamentalmente entre el amo y su esclavo, también se da en dos casos adicionales ${ }^{5}$ : en el acatamiento de un hombre libre que dependa económicamente de otro, sujeto denominado con el término " $\delta \mu \omega ́ \varsigma$ " [“dmốs"]

$\begin{array}{ll}4 & \text { Chantraine }(1968: 294-295) \\ 5 & \text { Pohlenz }(1956: 12)\end{array}$


(concepto que además hace referencia al esclavo capturado en la guerra); y además en la estricta obediencia que un hijo debe tener respecto a las órdenes de su padre, hecho que explica que en ciertas fuentes clásicas el concepto " $\pi \alpha i \tilde{\varsigma} "$ " "paîs"], "niño", también sea utilizado como sinónimo de esclavo con un sentido particularmente despectivo.

Segundo, la fuerte convicción de que este tipo de vínculo de sometimiento es acorde con un orden natural del mundo, orden que, a su vez, se ajusta a la voluntad divina. El sometimiento de los esclavos que el orden social humano ejerce, de este modo, aparecería legitimado por su encuadre con una disposición de la naturaleza que, en último término, se ajusta los designios sagrados de los dioses. La esclavitud, de este modo, adquiere para los griegos un carácter evidente e incuestionable que termina de consolidarla, en palabras de Max Pohlenz (1872-1962), como una "institución social fija".

A pesar de las dificultades suscitadas por la variedad terminológica empleada en la designación de los esclavos, el contraste entre la posición que el esclavo ostenta y la condición de hombre libre se percibe con claridad: a diferencia del primero, el "eleútheros", el hombre libre, si es capaz decidir sobre sí mismos y autogobernarse ${ }^{7}$. El origen etimológico de este concepto se encontrará en la raíz indoeuropea "leudh", concepto que, a su vez, significa "elevarse" o "subir", y que también se encuentra en término griego $\dot{\lambda} \lambda \varepsilon v \theta \varepsilon p i ́ \alpha$ [eleutheríâ] ("libertad"), y en el vocablo latino "liber" ("libre").

Como en el caso de doûlos, también una serie de conceptos afines serán utilizados junto con eleútheros para designar a la persona libre y, por definición,

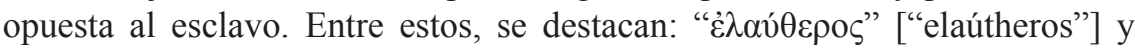

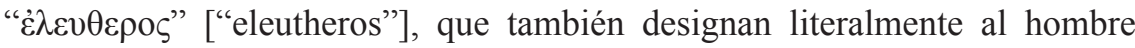

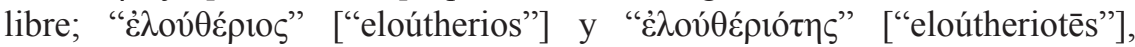

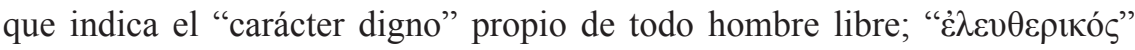
["eleutherikós"], relacionado con tener la "apariencia" de un hombre libre

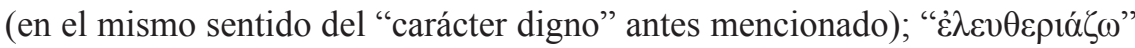
["eleutheriazoo"], "comportarse" con la prestancia adecuada de un hombre libre, especialmente referido a la condición de ciudadano y la posibilidad de participar en las decisiones de su polis; etc. ${ }^{8}$

Siguiendo la explicación ofrecida por Wener Jaeger (1888-1961), en el sentido de autonomía e independencia de esta idea griega de la libertad se podría identificar una doble dimensión: es individual, por cuanto alude

$6 \quad$ Pohlenz $(1956: 11)$.

$7 \quad$ Chantraine (1968: 294).

$8 \quad$ Chantraine (1968: 336-337). 
a la posibilidad del sujeto de revelarse frente a las órdenes, instrucciones o mandatos impuestos por un tercero o un grupo; pero también es colectiva, al simultáneamente involucrar la decisión de una nación de enfrentarse al dominio - o amenaza de domino - ejercida por otra9 ${ }^{9}$. En ambos casos, no obstante, esta noción griega de la libertad carece del sentido universal, indefinible, ético y metafísico que presenta en la modernidad, ya que, como destaca Chantraine, en el marco cultural heleno "libre" no necesariamente constituye un sinónimo de "hombre"10. Por tal razón, para Jaeger la libertad griega finalmente constituye un "concepto positivo del derecho político": se expresa concretamente en la participación directa de los individuos en las decisiones de la polis, consistiendo entonces - especialmente en Atenas - en una condición propia del "ciudadano", del miembro legítimo de la comunidad política, y no simplemente del "habitante" en ella.

\section{Nexo entre esclavitud y barbarie: su contraste con el sentido político de la libertad.}

El trasfondo político que la noción griega de libertad presenta, origina una diferencia clara entre la condición de hombre libre y el lugar que ocupan, dentro de la polis, niños, mujeres, extranjeros y esclavos, los cuales, de hecho, no participan en los procesos deliberativos de la política. Sin embargo, tomando en cuenta los alcances filosóficos y prácticos que este sentido de libertad presenta, el mayor contraste con la noción y condiciones de vida asociadas al hombre libre se percibe respecto de los esclavos. Este contraste, como veremos, independiente del sistema político de las polis, se plasma el marco jurídico, institucional y cultural de cada una de ellas, influyendo directamente en la consolidación de una imagen fuertemente negativa del esclavo, adjudicando a él una menor capacidad intelectual, moral y cultural que la de los hombres libres.

Al respecto, la interpretación de Chantraine permite inferir que la menor asignación de derechos políticos a los esclavos incide en la menor valoración social de éstos. La noción de un "deber inferior"11, señalará el lingüista francés, conduce fácilmente a la asignación de un "valor inferior", pudiendo considerarse entonces que es el orden jurídico finalmente refleja una convicción cultural que, a su vez, se materializa en la sociedad política. Desde esta perspectiva, la opinión ampliamente extendida en el mundo griego de

$9 \quad$ Jaeger (1997: 433).

10 Chantraine (1968: 13).

11 Chantraine, (1968:14). 
superioridad del ciudadano e inferioridad del esclavo, en el orden político y social de las polis se plasmaría tanto en el derecho del primero a participar de las decisiones políticas fundamentales (principalmente en el sistema democrático ateniense), como en la posibilidad de poseer y disponer de la conducción de la vida del esclavo ${ }^{12}$. La libertad que se ejerce en la sociedad política, así, aparece como el principal elemento diferenciador entre el ciudadano y el esclavo, y factor legitimador de su derecho a someterlo ${ }^{13}$.

Junto con su manifestación en el ámbito político, un concepto importante en la noción griega de libertad es la posibilidad de autodeterminación. Pohlenz lo interpreta como la noción central, atribuyéndole - junto con otros autores - una relevancia en la formación del carácter griego que se percibe de forma notoria en la forma como éstos encaran el conflicto bélico que los enfrenta con el Imperio persa, el cual es interpretado por los mismos griegos precisamente como una amenaza directa para la conservación de su libertad y su cultura ${ }^{14}$.

La concepción griega de autodeterminación presenta rasgos particulares. Entre éstos, determinante es su relación con la noción de "destino", cuya fuerza - dentro de la visión religiosa griega - no sólo se impone a la voluntad de los hombres, sino también a la voluntad de los mismos dioses ${ }^{15}$. A partir de ello, como se percibe en numerosos pasajes literarios, el hombre griego conduce su vida con la claridad que habita un mundo regido por fuerzas superiores a las suyas y frente a las cuales, ya sea por su origen divino, o por una disposición del destino, finalmente no tiene oportunidad de oponerse ni contravenir. Sin embargo, esta aparente limitación, bajo el punto de vista helénico, confiere un sentido altamente laudable a la intención de enfrentar ese destino ya fijado, asociando precisamente dicha acción con el ejercicio de la libertad que, a su vez, plasma todo su valor a la actitud heroica de los protagonistas retratados en las grandes obras de Homero y Hesíodo representan ${ }^{16}$.

De esta manera, si bien el griego expresa un respeto por la voluntad de las fuerzas superiores que determinan el funcionamiento del mundo y de los acontecimientos fundamentales de su propia vida, entiende como posible y loable la opción por confrontar este destino a pesar de la imposibilidad de su modificación: reconoce, por una parte, a los dioses y el destino el poder suficiente para infringir una muerte física, pero, por otra, no renuncia a la

12 Finley (1981:130-131).

13 Castillo (1962: 15).

14 Pohlenz (1956: 94-96).

15 Ruiz de Elvira (1975: 61).

16 Chantraine (1968: 10). 
posibilidad de escoger libremente la confrontación de su destino. Como concepto moral y existencial, entonces, la autodeterminación constituye una noción acorde con la naturaleza divina del mundo, y simultáneamente acorde con el discernimiento propio, coexistiendo ambos tipos de voluntad (divina y humana) en una armonía que no resta sentido al mundo ni limita la libertad humana ${ }^{17}$.

El influjo de este concepto de autodeterminación, en tanto elemento constitutivo de la noción de libertad que los griegos se atribuyen como rasgo propio, explica en gran medida el profundo rechazo que este pueblo expresa hacía la esclavitud. La historia bélica griega, como mencionamos, se desarrolla fundamentalmente a partir del anhelo de protección de esta noción específica de libertad, siendo a partir de ella que también se configure un orden social con roles y tareas de marcadas diferencias entre hombres libres y esclavos, sostenida principalmente en una concepción naturalista de la esclavitud donde la legitimidad del sometimiento forzado de los hombres se vincula directamente con la imagen desfavorable del "bárbaro".

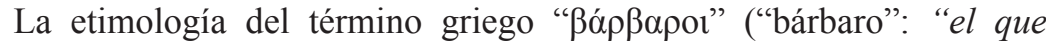
balbucea"), alude en un sentido despectivo a aquellos extranjeros que, caracterizados por no hablar griego, a oídos de los helenos se comunican a través de sonidos inentendibles o "balbuceos"18. Pierre Chantraine explicará como la palabra "bárbaro" se origina en la onomatopeya "bar-bar" con la cual los griegos hacen referencia, precisamente, a la acción de balbucear los sonidos incomprensibles con los cuales asocian las lenguas extranjeras, especialmente en el caso de los medos ${ }^{19}$. Es este mismo sentido, el lingüista y etimólogo sueco Hjalmar Frisk (1900-1984), destaca el marcado sentido de "bárbaro" como "extranjero" y "no griego"20, concepto que como explican los eminentes lingüistas ingleses Henry George Liddell (1811-1898) y Robert Scott (18111877), abarca a todos pueblo que no hablan griego, los cuales especialmente en el caso de los medos, adicionalmente se asociarán con la rudeza, brutalidad y salvajismo ${ }^{21}$.

El semblante de "bestialidad" e "irracionalidad" que el bárbaro adquiere los helenos, de este modo, se expresará en la idea de las menores capacidades intelectuales que el bárbaro manifestaría, incapacidad que originaría a su vez

17 Chantraine (1968: 10).

18 Guthrie (1988: 156).

19 Chantraine (1968: 163-164).

20 Frisk (1954: 219-220).

21 George, Scott (1940: 306). 
una tendencia a llevar su vida por las pasiones y apetitos y que, proyectadas en la convivencia política y social, imprimiría a este orden un permanente estado de desorden y $\operatorname{caos}^{22}$. A partir de esta caracterización, finalmente, el mayor contraste entre el bárbaro y el griego consistirá en la condición de hombre libre que el segundo presenta - de forma natural - frente al primero, hecho que legitimará su sometimiento forzado.

La identificación que el griego establece entre sí y el ejercicio de la libertad es, como expresa Werner Jaeger (1988-1961), uno de los conceptos centrales de la identidad y carácter del pueblo heleno ${ }^{23}$. La amplitud semántica

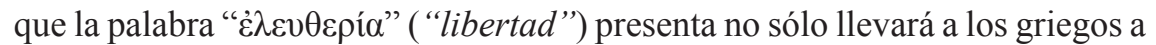
entender esta libertad como un atributo del sujeto, sino también además como una propiedad de la ciudad. Así, carente del sentido universal, indefinible, ético y metafísico que adquiere en la modernidad; la libertad griega consistiría en un concepto positivo del derecho político, el cual se expresa concretamente en la participación directa de las decisiones de la polis ${ }^{24}$. El hombre libre, por lo tanto, será para los griegos y especialmente para los atenienses del siglo $\mathrm{V}$ a. C. únicamente el ciudadano: el "membre légitime" de la comunidad política, y no simplemente el "habitante" de ella ${ }^{25}$. Por esta razón, sin por ello presentar la condición de esclavo, tanto niños, mujeres, extranjeros finalmente se verán excluidos de la intervención en las instituciones públicas ${ }^{26}$.

\section{Las dificultades prácticas y teóricas en la diferenciación entre esclavos y libres.}

En contraste con la claridad aparente que la imagen del esclavo tiene entre los griegos, una identificación más precisa sobre su naturaleza bárbara y el lugar que ocupa en la sociedad helénica antigua revela la presencia de algunas importantes dificultades. Éstas, en general, guardan relación con la ausencia de formas universales en la noción de esclavo y la función que se le asigna, poniendo en entredicho la certeza de la concepción griega de la esclavitud a pasar de las numerosas referencias presente en textos antiguos. Dentro de las dificultades destacadas por los estudiosos, cuatro nos parecen las más relevantes:

$22 \quad$ Guthrie (1988: 156).

23 Jaeger (1997: 433).

24 Jaeger (1997: 433).

25 Castillo (1962: 15).

26 Chantraine (1968: 336). 
En primer lugar, como Finley explica, desde el punto de vista del trabajo práctico la diferencia entre amo y esclavo se vuelve en varios casos difusa ${ }^{27}$. Si bien será a esclavos quienes corresponde desarrollar el extenuante trabajo de las minas y los molineros, en el caso de las labores del campo y el comercio éstas serán compartidas de igual forma con sus amos, trabajando en conjunto y cumpliendo con prácticamente las mismas tareas. Al interior de los hogares de la ciudad, por su parte, los esclavos domésticos desarrollarán un trabajo similar al que despliega la esposa, y en el caso de los esclavos del Estado sus tareas también encontrarán una coincidencia general con la de funcionarios pagados para tales menesteres, los cuales por cierto corresponden a ciudadanos y hombres libres. Para Finley, de este modo, no sería en la modalidad del trabajo que se realiza donde se evidenciaría la diferencia entre el hombre libre y el esclavo, sino en la categoría social del sujeto que realiza la labor en cuestión ${ }^{28}$.

Un segundo punto en que la separación entre amos y esclavos se dificultad se relaciona con la mencionada variedad terminológica con la cual - como señalamos - los esclavos son aludidos por parte de los griegos. Esta variedad terminológica, destacada por primera vez por Lotze en Metaxý Eleutherôn kai Doulôn (1959), oscila entre la designación de funciones - como

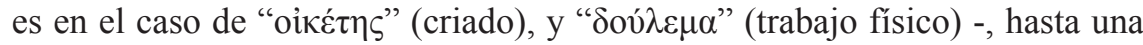
condición que podría asociarse a un fundamento naturalista - como la presente

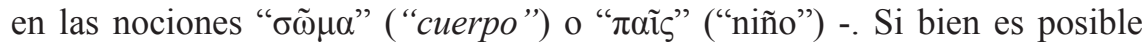
suponer que ambos sentidos coinciden finalmente en aludir a una situación de sometimiento por la fuerza (ya sea en el caso de las labores de un criado, o en el designio natural que lleva a ocupar el lugar de un hijo), la diferencia entre el nexo sanguíneo del sirviente con la prole es obvia y determina directamente el trato, el patrimonio o el lugar que uno u otro ocupan al interior de la familia.

Un tercer motivo que dificultaría la diferenciación libres-esclavos se encuentra en las prácticas concretas que la esclavitud presentó entre los griegos, especialmente durante el siglo $\mathrm{V}$ a. C. Al respecto, en un plano teóricofilosófico, el sometimiento forzado de hombres se justificaría por la menor capacidad intelectual y moral que algunos de ellos - los barbaros - presentarían tal como los testimonios de una serie de obras trágicas, científicas y filosóficas aseveran. Tal concepto, sin embargo, contrasta con la costumbre griega de esclavizar a los habitantes de las polis vencidas en conflictos bélicos, casos en los cuales el sometimiento no se estaría realizando a partir de la constatación de ese rasgo de inferioridad intelectual, sino a partir del hecho azaroso de la 
pérdida de una guerra. Algunos ejemplos de esta práctica se encontrarán en pleno siglo V a. C. durante el desarrollo de la Guerra del Peloponeso (431-404 a. C.), siendo los más conocidos la invasión ateniense a Torone el 422 a. C., a Escione el 421 a. C, y a Melos el 416 a. C., expediciones donde se asesina a prácticamente la totalidad de los varones, y se reduce a la esclavitud a mujeres y niños ${ }^{29}$, de forma similar a la conducción de las conquista espartana de Platea en el 427 a. C. Los testimonios de Tucídides, precisamente, son explícitos al señalar como los espartanos no acostumbraban a diferenciar a esclavos naturales de hombres libres en las ciudades conquistadas, procediendo a apresar y disponer de ambos indistintamente ${ }^{30}$, siendo el mismo autor a quien Plutarco (46/50-127) cita en su descripción de la terrible práctica de la krypteía: la cacería de ilotas que, como parte de la educación de los jóvenes espartanos, les exigía sobrevivir a la intemperie armados sólo con un puñal para, luego de ocultarse durante el día, salir en la noche a liquidar a cuantos de estos pudieran eliminar ${ }^{31}$. La dureza de los espartanos en su trato hacía los ilotas se ajustaría a la convicción lacedemonia expresada por Plutarco en la conocida afirmación que, en tierra espartana, "el libre era absolutamente libre y el esclavo absolutamente esclavo"32, perspectiva que se ajustaría con una concepción de la libertad que la entiende como una condición que se conquista, siendo propia entonces únicamente de aquellos sujetos con las condiciones naturales para hacerse de ella ${ }^{33}$.

Por último, en cuarto lugar, la carencia de estudios sistemáticos donde se examine en profundad el origen, sentido y legitimación de la esclavitud en el mundo griego, también dificulta la posibilidad de aproximarse con certeza a la imagen que los helénicos habrían tenido de los esclavos. En este punto, señalamos, la teoría sobre la esclavitud natural que Aristóteles formula en algunos capítulos el libro I de su Política constituye prácticamente el único trabajo de examen formal dedicado a la esclavitud, sustentando la legitimidad de su práctica en la diferencia natural de mando que habría entre los seres humanos. Tal diferencia, a juicio del Estagirita, se explica por los distintos grados de racionalidad presentes en el hombre libre y el esclavo, pues, a diferencia del segundo, el esclavo participa de la razón lo suficiente como para

29 Tucídides, Historia de la Guerra del Peloponeso IV, 116, 4; V, 32, 31.

30 Tucídides, Historia de la Guerra del Peloponeso VIII, 28, 4.

31 Plutarco, Vida de Licurgo VIII, 28, 3-7.

32 Plutarco, Vida de Licurgo VIII, 28, 11.

33 Patterson (1993: 158). 
entenderla, pero no al punto de poseerla ${ }^{34}$. Esta caracterización del esclavo, sin embargo, suscita importantes problemas en la definición del mismo, pues al disponer de la capacidad racional (aunque sea en un nivel rudimentario), el esclavo entonces ostentaría la condición de ser humano, y no de objeto animado como el Estagirita expresamente lo define casi al principio de Política. Esta diferenciación de grados de intelecto, que sustentaría la separación entre libres y esclavos, además, carecerá de una explicación mayor por parte del filósofo en esta obra, pudiendo de forma general identificarse para su esclarecimiento con la doctrina del doble intelecto (activo y pasivo) que desarrolla en Acerca del alma, la cual, no obstante, también adolece de una exposición certera respeto de la relación de estos dos intelectos y el origen último de su conformación.

De esta manera, a pesar de constituir un personaje central en la vida cotidiana del hombre griego (tanto en el hogar como en la sociedad), la noción helénica de la esclavitud se encontraría cubierta por un manto de ambigüedad y falta de claridad que, durante mucho tiempo, se asumió como una debilidad propia de los griegos en su caracterización del esclavo.

\section{La tesis de Lotze: las formas heterogéneas se sujeción en Grecia.}

Frente a la aparente falta de precisión de los griegos en su caracterización de la esclavitud, la posición de Detlef Lotze podría - desde nuestro punto de vista - identificarse en su sentido más amplio con la conocida imagen del "giro copernicano": es decir, la presumible ausencia de claridad en la conceptualización griega de la esclavitud no constituiría la evidencia de un problema profundo vinculado con la desprolijidad de los pensadores helénicos, sino más bien, describiría la forma - en este caso fundamentalmente heterogénea - en que la esclavitud verdaderamente se presentó y aplicó en la Grecia antigua. La pretensión de una definición uniforme de la esclavitud, así, más bien se ajustaría a la perspectiva de los estudiosos modernos, quienes esperan encontrar una caracterización definitiva y universal del esclavo griego que, sin embargo, estaría totalmente alejada de la visión histórica helénica, conformada por una serie de lecturas y prácticas respecto de la esclavitud directamente relacionadas con las diversas concepciones de la política, la ética y el ser humano en las distintas polis.

Adhiriéndose a esta lectura, e intentando dar cuenta de la complejidad que el escenario griego presentaría respecto de la práctica de la esclavitud, Finley, Vernant y varios helenistas de la segunda mitad del siglo XX tienden a coincidir en aceptar la diferencia entre un sistema de "esclavitud-dependencia" o "servidumbre" (donde el "esclavo" administra el proceso productivo, 
cancelando un monto prefijado de renta al propietario), y uno de "esclavitudmercancía" (donde el "esclavo" participa como un elemento material de un proceso productivo dirigido completamente por el propietario) ${ }^{35}$. Esta clasificación, grosso modo, permite diferenciar de mejor forma la situación de los esclavos-mercancía en Atenas con, por ejemplo, los ilotas y periecos de Esparta, los penestes de Tesalia, los marindinos de Heraclea, los gymnetes de Argos, etc., más cercanos a la idea de "esclavitud-dependencia".

Entre los testimonios antiguos que sustentan la existencia de esta separación, la del historiador Teopompo de Quíos (380-323 a. C.) en el libro decimoséptimo de su Historia es el más importante. La referencia, entregada por el orador y retórico griego Ateneo de Náucratis (s. II) en el libro VI de su Banquete de los eruditos, señalada:

"Los quiotas fueron los primeros griegos, después de los tesalios y los lacedemonios, que se sirvieron de esclavos

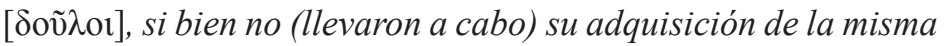
manera que aquéllos. En efecto, los lacedemonios y los tesalios,

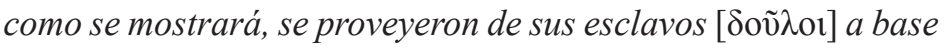
de los helenos que habitaban antes el territorio que ellos poseen ahora; los lacedemonios, a base de aqueos, y los tesalios, de perrebos y magnesios. Y llamaron a los pueblos esclavizados los unos, ilotas, y los otros, penestas. En cambio, los esclavos

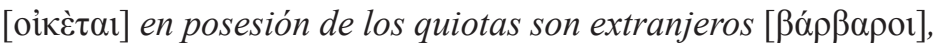
y pagan un precio por ellos ${ }^{, 36}$.

De ser así, no habría existido entre los griegos un significado ni una noción uniforme de "esclavitud", esto, en razón de una pluralidad de prácticas

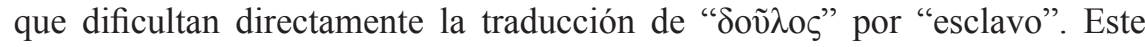
concepto, como bien explica Bernat Montoya a partir de los estudios de MarieMadeleine Mactoux, encierra una connotación "moderna" que no da cuenta de las formas empíricas en que la esclavitud se dio entre las distintas polis griegas, ni tampoco de la concepción teórica que éstos desarrollan a partir de la figura del bárbaro ${ }^{37}$. Esta connotación moderna, de hecho, entiende la esclavitud como una práctica que contradice y violenta una condición humana universalmente definida por la igualdad y la libertad del individuo: así, para dos

$35 \quad$ Montoya (2014: 276).

36 Ateneo, El banquete de los eruditos VI, 265 A, c.

37 Montoya (2014: 274). 
personajes emblemáticos del pensamiento político modernos como son John Locke (1632-1704) y Jean-Jacques Rousseau (1712-1778), la esclavitud se opone directamente a una libertad natural ajena a toda forma de sometimiento por la fuerza y coacción en la posibilidad de orientar la vida propia ${ }^{38}$.

Volviendo al texto de Teopompo citado por Ateneo, el mismo Montoya

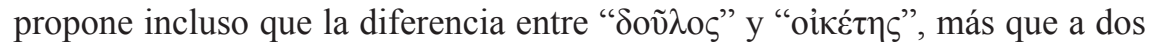
formas de esclavitud, corresponderá a dos formas de "trabajo dependiente" originadas en momentos distintos de la historia política y económica de las polis ${ }^{39}$. El primer concepto se ajustaría a una forma más arcaica de esclavitud, propia de un modelo de sociedad patriarcal que - entre otras características entiende al esclavo como parte de la familia (en el sentido de habitar con ellos en el mismo hogar), y donde su trabajo fundamentalmente es de apoyo a las labores desarrolladas por los amos y dentro de los márgenes de una economía doméstica circunscrita básicamente al autoconsumo. En el caso del segundo concepto, el esclavo ya no se ajustaría a ese personaje que trabaja junto con sus amos y que reside en el hogar familiar, correspondiendo más bien a un "instrumento animado" (en la conocida terminología aristotélica) que forma parte del proceso de producción, propio de las polis del periodo clásico que alcanzan la autosuficiencia económica y la independencia política.

\section{Conclusiones}

La propuesta interpretativa de Lotze marca un hito en le estudio de la esclavitud en el mundo griego, influyendo de forma directa en especialistas como connotados Finley, Vernant y otros. Desde el punto de vista cronológico, su planteamiento coincide con el distanciamiento que los helenistas manifiestan con otra tesis clásica y altamente influyente del pensamiento antiguo: la teoría del "milagro griego".

Originada en la interpretación que John Burnet (1863-1928) desarrolla en Early Greek Philosophy (1892), la tesis plantea que el pensamiento filosófico que surge en Grecia constituye una suerte de evidencia de la genialidad del pueblo helénico y su talento prácticamente natural para la reflexión racional, el cual, dado el contexto cultural dominado por el influjo de la creencia mitológica, representa un "milagro" para la civilización occidental. A pesar de la forma un tanto circular de la estructura de su argumentación, la tesis de Burnet prevalece durante décadas, dando paso a lecturas disidentes recién en la década de 1960 con el trabajo de Vernant, Les Origines de la pensée

38 Locke (2010: 39-41), Rousseau (2012: 39-44).

39 Montoya (2014: 277).

96 
grecque (1962) y Mythe et pensée chez les Grecs (1965). En contraste con la omisión que Burnet realiza del contexto histórico y cultural en el cual surge la filosofía, Vernant considera una serie de factores tales como la geografía, los procesos de colonización y fundación de las polis, la actividad marítimocomercial de los griegos, las características idioma, la ausencia del influjo de una casta sacerdotal en Grecia, el surgimiento de la democracia en Atenas, la dimensión oral en la transmisión del conocimiento, etc., deduciendo entonces que la aparición filosofía se explica por una pluralidad de factores vinculados entre sí que, básicamente, configuran un escenario acorde para su inicio. Esta interpretación, nos parece, se ajusta al fondo de la lectura que Lotze propone sobre la esclavitud, destacando, precisamente, la existencia de un marco cultural complejo, heterogéneo y diverso propio de las características de las polis que, reconociéndose en torno a una misma identidad "griega", expresan su autonomía al momento de organizarse política y económicamente.

El apego que las lecturas previas a las de Lotze manifiestan hacía las fijaciones conceptuales precisas, identificación de fechas exactas y delimitación de procesos ordenados con claridad, desde nuestra perspectiva expresa el influjo de una visión del ejercicio reflexivo originado en la concepción de la "razón instrumental" que desarrolla la modernidad. Bajo esta lectura, el "éxito" de la indagación reflexiva se conseguiría precisamente con la delimitación conceptual exacta del objeto de estudio examinado, objetivo que se consigue mediante el empleo riguroso de métodos sistemáticamente aplicados como predica, por ejemplo, el racionalismo cartesiano del siglo XVII, el empirismo del siglo XVIII y especialmente el positivismo de principios del siglo XIX. Esta última será la corriente quizás más influyente en la tradición filológica clásica que se empieza a desarrollar en Europa a mediados del siglo XIX y principios del XX, especialmente en Alemania e Inglaterra, donde eminentes estudiosos emprenden la compleja labor de la ordenación cronológica de los textos de Platón, la fijación del proceso de evolución del pensamiento de Aristóteles o la separación entre obras auténticas y apócrifas en los diversos autores clásico, desarrollando para esto métodos como la estilometría de Lewis Campbell o la indagación genético-evolutiva de Werner Jaeger.

Desde nuestra lectura, es frente a esta concepción específica de la indagación reflexiva que la pluralidad de conceptos griegos para denotar al esclavo se percibe - por la baja probabilidad de fijación conceptual - como una "debilidad" en la comprensión griega del fenómeno de la esclavitud y, consecuentemente, una dificultad para su investigación. Lotze, de este modo, toma distancia tanto con una interpretación particular de la esclavitud - y altamente predominante entre los estudiosos de su época -, como frente a la 
opción metodológica - también predominante - para investigarla, generando un espacio importante para la consideración del contexto cultural y una concepción heterogénea de las formas de aplicación de ésta.

La separación que mencionamos entre una modalidad de "esclavitudmercancía" y una de "esclavitud-servidumbre" - herederas ambas de la lectura lotziana -, permite disponer de elementos valiosos para examinar desde nuevas perspectivas aquellas dificultades que marcan el estudio moderno sobre la esclavitud griega antigua, interpretada por la tradición de investigadores previos a Lotze - como vimos - como una institución política y social uniforme en el mundo griego. En tal sentido, frente a la complejidad que representa diferenciar amo y esclavo a partir del trabajo práctico que ambos realizan, el abandono de esta idea de uniformidad de esclavitud griega permite diferenciar con mayor claridad el tipo de labor desarrollada entre esclavos, y de ellos respecto del hombre libre (cuyo espacio de expresión de la libertad presenta, adicionalmente, un sentido político relacionado con el ejercicio de la ciudadanía). Así, labores como el trabajo en molinero y minas corresponderían a la forma de esclavitud-mercancía, mientras que las actividades del campo o el comercio, a la esclavitud-servidumbre, pudiendo conciliar, además, la ya mencionada amplia gama de conceptos griegos empleados para referirse al

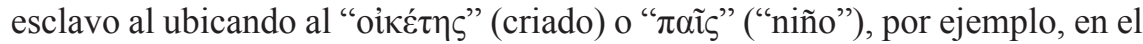
grupo de la esclavitud-servidumbre (por el mayor grado de vinculo que pueden desarrollar con el amo), mientras que el " $\sigma \tilde{\omega} \mu \alpha$ " ("cuerpo") y " $\delta$ ov́ $\lambda \varepsilon \mu \alpha$ " (trabajo físico) con la esclavitud-mercancía (especialmente por el carácter de objeto que ambas denominaciones resaltan). Finalmente, el problema de las formas disimiles en que los griegos se posicionan frente a la separación entre libres y esclavos, rechazando por una parte el sometimiento forzado de otros griegos, pero aplicando esta práctica en el contexto de la guerra, se puede interpretar como mucho más comprensible con la noción de esclavitudservidumbre, la cual no requiere necesariamente de una legitimación sostenida en la disposición natural del esclavo para ser sometido (debido a su condición de bárbaro), pues, la guerra también hace notoria - de forma natural - la diferencia entre los hombres capaces de conquistar su libertad, y aquellos incapaces de protegerla.

El único punto que parece no conseguir una respuesta apropiada a partir de la diferenciación entre esclavitud-mercancía y esclavitud-servidumbre, es el referente a la ausencia de una reflexión griega sistemática y formal sobre la esclavitud. Dicha ausencia, si bien - ya en el orden de la especulación podría explicarse por factores circunstanciales como el extravío de gran parte de la literatura de los autores clásicos griegos o, incluso, simplemente por el 
conocido espíritu práctico helénico que Aristóteles expone criticando a los que pretenden "demostrar lo que es claro por lo que es oscuro" ", los testimonios escritos disponibles también parecen indicar la presencia de una tensión entre la postura naturalista de la esclavitud-mercancía, y la forma un tanto convencional de la esclavitud-servidumbre. De esta manera, el sometimiento mediante la guerra (propio de la noción de esclavitud-servidumbre) será un tópico central en diversos pasajes de los textos homéricos ${ }^{41}$, donde la captura de principalmente de mujeres no se ajustará a una fundamentación naturalista vinculada con la condición bárbara de las prisioneras, sino a la obtención del triunfo en el combate armado; en contraste con la visión esclavista natural bosquejada por autores trágicos como Sófocles ${ }^{42}$ y Eurípides $^{43}$, suerte de antecedente de la teoría del determinismo natural que Hipócrates formula en Sobre el aire, el agua y los lugares, y que más adelante Aristóteles termina de plasmar en la ya aludida teoría de la esclavitud natural de Política. Por esta razón, si bien la tesis de Montoya que sitúa la esclavitud-mercancía y esclavitud-servidumbre como dos momentos o etapas en el desarrollo histórico del concepto griegos de la esclavitud parece tener asidero, también parece evidente la presencia de un concepto de esclavitud por guerra aún en el siglo V a. C., reforzando entonces la heterogeneidad de las maneras en que los griegos concibieron y ejercieron la esclavitud en sus respectivas polis.

\section{BIBLIOGRAFÍA.}

ARISTÓTELES (1995). Fisica. Madrid: Gredos.

--- (1994). Política. Madrid: Gredos.

ATENEO (1990). El banquete de los eruditos VI. Madrid: Gredos.

CASTILlO, M. (1962). La esclavitud en la filosofía político-jurídica de la Antigua Grecia. Santiago: Editorial Universitaria.

CHANTRAINE, P. (1968). Dictionnaire étymologique de la langue grecque. Histoire des mots. Paris: Editions Klincksieck.

EURÍPIDES (2000). Tragedias vol. I. Madrid: Gredos.

FINLEY, M. (1981). La Grecia antigua. Economía y sociedad. Barcelona: Ediciones Crítica.

GEORGE, H., SCOTT, R. (1940). A Greek-English Lexicon. Oxford: Oxford University Press.

\footnotetext{
$40 \quad$ Aristóteles, Física II, 193a, 5.

41 Ver Homero, Iliada, I, 17-20; VI, 450-465; XVI, 830 y sgte.; XX, 190 y sgte.

42 Sófocles, Áyax, p. 71.

43 Eurípides, Ifigenia en Áulide, 1400.
} 
FRISK, H. (1954). Griechisches Etymologisches Wörterbuch. Heidelberg: Carl Winnter Universitateverlag.

GUTHRIE, W. (1998). Historia de la filosofia griega volumen III. Madrid: Gredos.

HOMERO (2000). Ilíada. Madrid: Gredos.

JAEGER, W. (1997). Paideia: los ideales de la cultura griega. Bogotá: Fondo de Cultura Económica.

LOCKE, J. (2010). Ensayo sobre el gobierno civil. Buenos Aires: Prometeo.

LOTZE, D. (1959). Metaxý Eleutherôn kai Doulôn. Studien für Rechlsslellung unfreier Landbevölkerungen bis zum 4Jh. v.Chr.Berlin: Ost.

MONTOYA, B. (2014).“La marginación social como factor de identificación de la esclavitud en la antigüedad“, Dipendenza ed emarginazione nel mondo antico e moderno: atti del XXIII Convegno Internazionale GIREA dedicati alla memoria di Franco Salerno, 273-284.

PATTERSON, O. (1993). La Libertad: la libertad en la construcción de la cultura occidental. Santiago: Andrés Bello.

POHLENZ, M. (1956). La liberté grecque, nature et évolution d'un idéal de vie. Paris: Boulevard Saint-Germain.

PLUTARCO (1985). Vidas paralelas I (Vida de Licurgo). Madrid: Gredos.

ROUSSEAU, J. J. (2012). El contrato social. Madrid: Espasa Calpe.

RUIZ DE ELVIRA, A. (1975). Mitología clásica. Madrid: Gredos.

SÓFOCLES (2000). Tragedias. Madrid: Gredos.

TUCÍDIDES (2006). Historia de la guerra del Peloponeso libros I-II. Madrid: Gredos.

--- (2000). Historia de la guerra del Peloponeso libros VII-VIII. Madrid: Gredos.

VIDAL-NAQUET, P. (1992). La democracia griega: ensayos sobre historiográfica moderna y antigua. Madrid: Akal. 